\title{
Sustainability Balanced Scorecard as Cost Accounting Instrument for Small and Medium Sized Companies
}

\author{
Peter Achenbach Dipl. Ing. ${ }^{\text {I* }}$ \\ ${ }^{1}$ DG Industries GmbH, Am Berg 12, 65779 Kelkheim, Germany
}

\begin{abstract}
This paper deals with the sustainability management concept of the Sustainability Balanced Scorecard (SBSC), which is a further development of the Balanced Scorecard (BSC) developed by Kaplan and Norton in the 1990s. In the SBSC the four classical perspectives of the BSC, which comprise "Finance", "Customers", "Internal Processes" and "Learning \& Development", are expanded to include environmental and social aspects ("Non Market") enabling sustainability aspects to be fully integrated into the strategic management of companies. After a generic presentation of the elements of a BSC this paper shows the individual steps for the implementation of an SBSC, which as a heuristic for the creation of a target system, can contribute to the transformation of sustainability strategies into actions. The "openness" of the SBSC makes it possible that sustainability is not limited to a small number of companies that are primarily active in ecologically and socially oriented sectors, but appears practicable for all those companies that want to improve their performance in all three dimensions of sustainability through increases in ecological- and socialeffectiveness and rises in ecological- and social-efficiency. By overcoming the "trade-off" between profit orientation and the focus on sustainability it is thus possible to achieve through enlarged consumer- and producer surplus an important contribution to the overall increase in the welfare economy.
\end{abstract}

\section{Introduction}

The importance of dealing with sustainability aspects is increasing daily for companies. This is due not least to global developments such as climate change, scarcity of resources and energy, but also to increased demand from the stakeholders associated with the respective companies which ultimately issue the "Licence to operate". The efficient management of economic, ecological and social shortages is regarded as a central task of management [1]. Corporate sustainability management deals with this challenge of overcoming scarcities and thus makes a major contribution to securing the future viability of the company and also the natural and social foundations. However, if operational sustainability management is not operated effectively and efficiently considerable deficits can occur in the company. In order to overcome these deficits the use of an SBSC, which has been derived from the BSC already used in many companies and supplemented by sustainability aspects, appears to be the concept of choice. The extent to which an SBSC can contribute to the identification, alignment, measurability and control of sustainability aspects will be examined in more detail below. The focus here will be on clarifying to what extent the classic understanding of the "trade-off" between profit and sustainability can be eliminated and instrumentalized in a complementary way to the benefit of companies and society.

\section{Current state of the concepts and instruments of sustainability management}

Figure 1 shows the main users who use some of the concepts and instruments of sustainability management mentioned in the selected list. In total, 9 concepts can be used and 37 instruments, of which

\footnotetext{
* Corresponding author: peterachenbach@t-online.de
} 
three concepts and sixteen instruments were selected as examples here. It can be seen that the SBSC can be used by all main users to identify, quantify and control the dominant sustainability challenges (ecoeffectiveness, socio-effectiveness, eco-efficiency, socio-efficiency). With regard to the other two selected concepts (SCM - Supply Chain Management, TQEM - Total Quality Environmental Management) it becomes apparent that they do not serve the complete value chain of supporting activities in companies which further underlines the integrative function of an SBSC.

In another study, a taxonomy of integrated reporting has been developed. There, a coding catalog with criteria and key figures and the degree of conformity of business/sustainability reports with identify report types has been developed, with the result that reports with an integrated focus show in particular higher connectivity and stronger compliance with sustainability standards/guidelines and emphasize the stakeholder perspective. [2].

The explanations of the individual concepts and instruments including their strengths and limitations can be read in detail under [3].

\section{Figure 1}

Selected Concepts and Instruments of Sustainability Management

\begin{tabular}{|c|c|c|c|c|c|c|c|c|c|}
\hline Concept/ Instruments & \multicolumn{9}{|c|}{ Main User } \\
\hline $\begin{array}{l}\text { Concept } \\
\end{array}$ & Controlling & Purchasing & $R \& D$ & Marketing & $\mathrm{HR}$ & Production & Accounting & Strategic Planning & Sales / Logistics \\
\hline SBSC & 0 & 0 & 0 & 0 & 0 & 0 & 0 & 0 & 0 \\
\hline SCM & 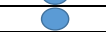 & O & & 0 & & 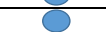 & 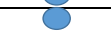 & 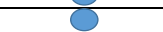 & 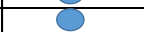 \\
\hline TQEM & 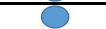 & 0 & & O & 0 & 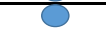 & 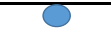 & 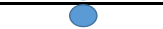 & 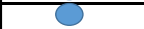 \\
\hline Instruments & & & & & & & & & \\
\hline Audit & 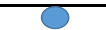 & 0 & & & & T & 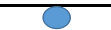 & & 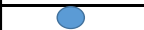 \\
\hline Benchmarking & 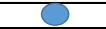 & & 0 & & & 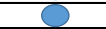 & 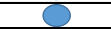 & & 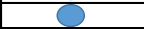 \\
\hline Report & 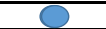 & & & 0 & 0 & & 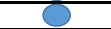 & & \\
\hline Checklist & 5 & 0 & & 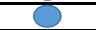 & & J & & & J \\
\hline Cross - Impact- Analysis & $\Gamma$ & & 0 & & & & & 0 & \\
\hline Env. Shareholder Value & 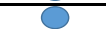 & & & & & & 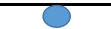 & & \\
\hline KPI & 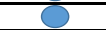 & & & 0 & & 0 & 5 & O & J \\
\hline Costing & 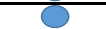 & & & & & & 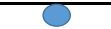 & & \\
\hline Ecological Balance & 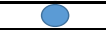 & 0 & & & & J & & & \\
\hline Eco - Design & & & 0 & 0 & & 0 & & & \\
\hline Eco - Efficiency Analysis & 0 & 0 & & & & 0 & & & \\
\hline Eco Rating & & & & & 0 & & J & & \\
\hline Risc Analysis & 0 & & & & & O & 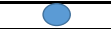 & J & \\
\hline Socio Balance & & & & J & $J$ & & S & 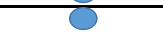 & \\
\hline Stakeholder Value & & & & & O & & J & J & \\
\hline Material Flow Analysis & 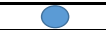 & & 0 & & & $\Gamma$ & & & \\
\hline
\end{tabular}

\section{Methodology and delimitations}

In order to deal with the topic of the presentation of an SBSC for the purpose of the measurability of sustainability aspects the BSC will be explained. On the basis of a literature search the SBSC will be theoretically described. Finally, the ecological, social and economic challenges of the SBSC are enumerated in order to illustrate the further development potential of this concept (refer to Chapter 5).

\section{Sustainability and cost accounting}

In the following, the concept of sustainability and its management will be described by presenting specific criteria (chapter 4.1) and methodologies (chapter 4.2).

\subsection{Sustainability}

This concept of sustainability received increased public attention when it was defined as follows in the 1987 UN report "Our Common Future" ("Brundtland Report"): "Sustainable development is development that meets the needs of the present without compromising the ability of future generations to meet their own needs" [4]. Profits that can be achieved in the short term, which are demanded above all by the capital markets, often contradict the long-term safeguarding of a company's existence. Incentive systems and management instruments geared to short-term goals also lead to a subordinate importance of environmentally and socially compatible business practices for the individual employee. An increasing shareholder value from the point of view of sustainability therefore demands a long-term orientation of a company through its business strategy. The consistency between sustainability indicators at national level and by companies has been investigated in [5]. Among other findings, it can be shown that 
indicators for each SDG are developed at the national level, but lag behind on several topics at the corporate level. Consequently, there is potential for improvement with regard to the definitions of KPIs in order to optimally align companies with the achievement of the 17 global sustainability goals. In further work, motives of small and medium-sized enterprises for the application of sustainable social and environmental practices have been investigated. The results show that SMEs use a complex mix of symbolic and substantive CSR practices to increase the legitimacy and sustainability of their activities, with the intended result of strengthening social commitment, reputation and image [6]. Furthermore, a sustainable approach to business requires the integration of ecological and social aspects in addition to economic aspects when making decisions. Depending on which of the three possible approaches to sustainability - economic, ecological or social - is chosen, a distinction can be made between various criteria which will be presented below [7].

\subsubsection{Six Criteria}

Figure 2 shows the six criteria of corporate sustainability.

Figure 2

Six Criteria for Corporate Sustainability

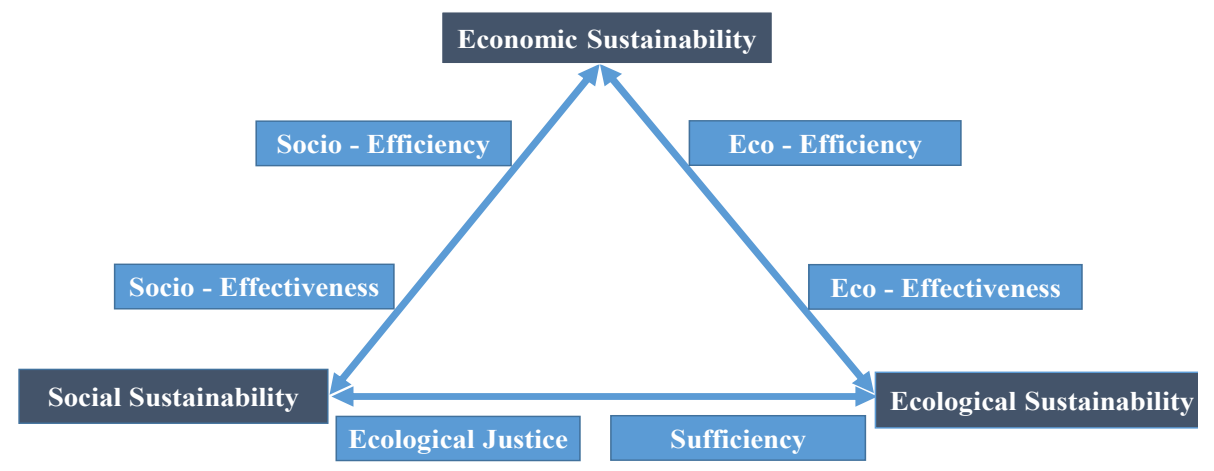

Looking at the perspective of economic sustainability the central question is how the financial success of a company can be increased through the sustainable management of natural and social capital. In essence, this is about increasing the eco- and socio-efficiency of the company. The origins of ecoefficiency can be found in the concept of efficiency according to which the aim is to achieve a maximum or a given output with a given or minimum input of resources according to the economic principle as well as in the demand for adequate consideration of ecological aspects within the system boundaries considered. The term "added value" in the form of the desired output as well as "harmful creation" are also of central importance where the (negative) environmental or social impacts of the product or process under consideration are recorded. Priority should be given to economically oriented eco-efficiency in the form of an objective based primarily on economic principles, but always with mandatory consideration of ecological aspects, which can be summarised in the concept of sustainable eco-efficiency. This manifests itself in a permanent creation of added value in the form of increased output with a simultaneous reduction of the input and reduction of the environmental impacts associated with the system. The analysis of the system-related environmental impacts can be carried out on the basis of weighted criteria specified in the form of energy consumption, material consumption, land consumption, emissions, risk potential and toxicity potential [8]. The technical term "socio-efficiency" describes the social effects of a product or process in relation to the total costs for the end consumer. This can be represented by key figures to be determined, which can find their formulation in value-added or productrelated work, for example in the form of "person hours per value added" or "product life cycle costs". If both eco-efficiency and socio-efficiency analysis are available for a specific system a combination of the generated eco-efficiency and socio-efficiency portfolios can be used to create an overall graphic presentation of all evaluation results in the form of a three-dimensional illustration (abscissa: costs; ordinate: environmental impacts; z-axis: social impacts). The result is a comprehensive socio-ecoefficiency analysis of the relevant product or process which identifies, quantifies and evaluates not only the economic but also the ecological and social aspects of the analysed target. On the basis of the results obtained various product or process alternatives that generate the same benefits can then be compared in 
terms of costs, environmental and social aspects using relative indicators. With regard to ecological sustainability, the goal is not only a relative improvement compared to value creation but an absolute improvement of the environmental situation by optimizing the entire product life cycle with the help of an assessment of the environmental impacts according to global problematic areas. In addition to the ecoeffective satisfaction of needs by the economy a change in the purchasing behaviour of consumers under the heading of sufficiency is also required in order to improve the ecological dimension of sustainability. In the context of social sustainability the socio-effectiveness of a company's activities must be designed in such a way that it can withstand assessment in the context of general societal challenges and "does the right thing". Social sustainability is completed by ecological justice describing the treatment of natural resources that includes the rights of all living beings. In addition to humans the rights of animals and plants are also included in the concept. Ecological justice in the sense of a holistic approach thus deals with social and spatial distributive and procedural justice in questions of human interaction with the biotic environment. A central task of corporate management is to manage these six criteria of operational sustainability in order to contribute to securing the future viability of the company without neglecting the natural and social foundations that form the basis of this future viability. In principle, it was primarily large multinational companies that first introduced corporate sustainability management or implemented Corporate Social Responsibility (CSR) [9]. The European Commission sees as "pioneers in the development of corporate social responsibility mainly larger companies" [10]. However, dealing with sustainability issues increasingly also applies to small and medium-sized enterprises (SMEs), which represent more than $99 \%$ of the German business community. They are the main pillar of the economy and therefore of at least equal importance for its transformation towards sustainability as large enterprises. Companies are increasingly introducing environmental and social management systems (e.g. ISO 14001, EMAS, ISO 26000, SA 8000) in order to align their sustainability management accordingly. However, these systems represent only partial solutions as they only take into account certain dimensions of sustainability with the consequence that they are isolated from general management systems. The weak points of environmental- and social- management systems therefore lie in their lack of focus on the financial success of companies. In order to make a contribution to the sustainable development of a company environmental- and social management systems must also include the economic dimension of sustainable development. A value orientation of sustainability management can guarantee this. For effective sustainability management it is also necessary to make use of strategic instruments as well as to ensure operational implementation. Furthermore, long-term risks and opportunities are often not taken into account, the management systems are not strategically oriented and often do not reach the core business. Overcoming these deficits thus becomes a decisive challenge for effective and efficient sustainability management. In the following chapter in particular one concept is presented that makes such sustainability management possible

\subsection{Concepts of sustainability management}

In recent years, scholarly interest in corporate social responsibility (CSR) has increased; however, research on the relationship between CSR and firm performance has revealed a complicated relationship. Part of the basis for the generally positive relationship between CSR and corporate performance comes from a reduction in agency costs (based on Behavioural Agency Theory) [11], which can be managed using appropriate sustainability concepts with suitable methods and tools. Nine concepts are listed in the literature of which the BSC and the SBSC derived from will be examined in more detail below as a sustainability management concept.

\subsubsection{Balanced scorecard}

The basic idea of this concept was to derive qualitative and quantitative objectives and indicators from a company's vision and strategy. In order to promote a multidimensional and balanced way of thinking in deriving individual strategic goals from the strategy, Kaplan and Norton proposed four perspectives for the BSC $[12,13,14]$, on the basis of which managers should regard the value chain of their company: Finance; - Customers; - Internal Processes and - Learning and Development (refer to Figure 3). The goals thus achieved are linked to each other and to the financial goals which are reflected in the financial perspective. The developed BSC focuses on achieving financial goals which is why the strategic goals of the financial perspective are at the top of the causal chain. The logic of the causal chain is that optimisation of operational performance and new products and services are directly or indirectly linked to a better financial result [15]. By creating this system of strategic goals the next step is to allocate metrics to the individual goals to create a balanced set of key figures. When developing the indicators care must be taken to ensure that, in addition to the traditional "Lagging Indicators", so-called "Leading 
Indicators" are also taken into account [16]. These leading indicators, also known as "Early Indicators", measure the reasons that should lead to the desired effects in the future - measured with "Lagging Indicators". After deduction of the goals, the formation of cause-effect relationships and the generation of key figures further values are to be defined which additionally specify the corresponding strategic goals. This defines the target levels for the strategic goals which can be achieved through appropriate strategic measures. The definition of strategic measures in the form of a "Road Map" is at the same time the last step in setting up a BSC which forms a kind of „,conceptual framework” [17]. The number and type of perspectives used and the content derived from the strategy must be determined individually by each company and enable the implementation of strategies in actions. When the BSC is extended from a key performance indicator system to a strategic management system the following steps can be distinguished [18]: - Translating the corporate vision into strategy: Consensus can be reached on the strategy which often exists only implicitly in the minds of managers. - Communication of the strategy: Top-down from the management to the downstream areas. Matching the objectives of the individual employees, the teams or the departments with the strategic objectives of the company or business unit strategy takes place. - Planning and targets / strategic feedback and learning: The defined strategic activities link the strategic planning with the medium-term and operative planning. A distribution of resources coordinated with the corporate strategy is achieved. Key performance indicators enable a permanent comparison between target and actual results and verification of the appropriateness of the assumptions made. This induces a learning process and enables continuous work with the BSC. - The final goal is an organization in which all employees are consistently oriented and aligned to the strategy. In line with the structure of the classic BSC the financial perspective is the primary objective responsible for "increasing shareholder value" [19], the achievement of which is measured using key performance indicators such as ROI, ROCE or EVA.

Figure 3

The Balanced Scorecard

\section{Balanced Scorecard Framework*}

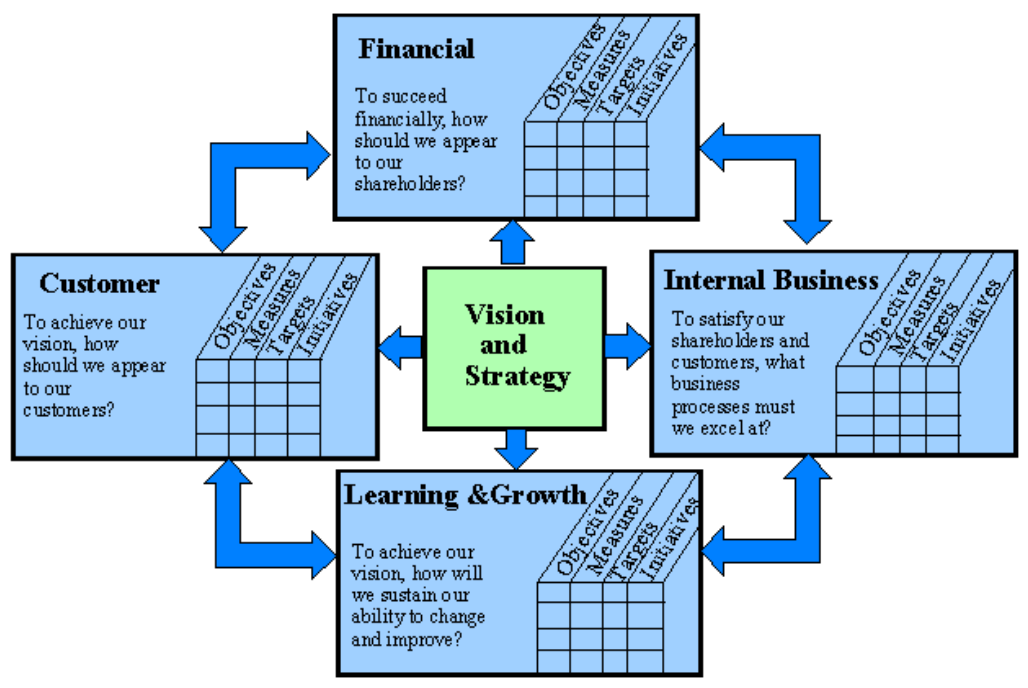

Based on Kaplan's and Norton's practical experience there are two basic strategies for achieving this goal: Sales growth and productivity. If a company pursues a growth strategy it looks for new products, markets and customers as well as the increase of the benefit to the client in order to increase turnover and profitability. An increase in productivity is primarily achieved through cost reductions and efficiency increases in existing activities or processes. From the customer's perspective it is considered which segment of the customer is to be dealt with, with the aim of achieving the economic success of the company. The core performance indicators are the following: Customer profitability; Customer satisfaction; Customer loyalty; Customer acquisition; Market share. Leading indicators for the lagging indicators listed before are derived from one of the following individual differentiation strategies: Strategy of product leadership; Strategy of customer loyalty; Strategy of operational excellence. Targets and indicators for the internal process perspective must be aligned with this strategy and reflected in the value proposition for customers. The sub-processes can be oriented towards the value chain "Innovation", "Operation/Production" and "Customer Service"(lagging indicator) with their key figures (leading 
indicator) regarding "Quality", "Costs" and "Time" such as "punctual deliveries", "ppm error rate", "yield", "material waste" or "process costs". In the learning and development perspective the required abilities/motivation of the employees as well as the necessary structure organizations and operational organizations are described which are needed for the objective accomplishment of the other perspectives specified before. Proposed are the categories "Employee Loyalty", "Employee Productivity" and "Employee Satisfaction" (lagging indicator) with the corresponding leading indicator "Working Climate", "Infrastructure" and "Personnel Potential". The SBSC as a further development of the BSC will be presented in the following Chapter 4.2.2

\subsubsection{Sustainability balanced scorecard}

Through its value-oriented view and the transformation of corporate environmental strategies and social strategies into operational parameters it represents a suitable concept and is able to answer the question of the measurability of sustainability in companies. The purpose of the SBSC is to integrate the three pillars of the sustainability concept into the respective strategy of the company whereby the company performance is to be increased through improved sustainability contributions of all criteria. Since the conventional BSC hardly takes environmental and social aspects into account the approach of an extension of the BSC by an additional perspective with regard to environmental and social aspects is recommended to be used to formulate an SBSC. A so called "Non-Market Perspective" is introduced ensuring that those environmental and social aspects that have not yet been considered are also integrated which appear essential for the successful implementation of the company strategy. The steps necessary to create an SBSC are explained as follows and can be obtained from Figure 4 [20, 21]. The first step is the selection of the strategic business unit for which an SBSC is to be created. A strategy for this unit must be available or formulated for this purpose. The second step is to determine the environmental and social exposure of the business unit. The aim is to draw up as complete as possible a catalogue of requirements for the strategically relevant aspects of the business unit. In the last main step the strategic relevance of environmental and social aspects is determined. The individual perspectives are examined starting with the financial perspective up to the non-market perspective and all identified environmental and social aspects are checked for their strategic importance. Three levels can be classified with regard to the strategic relevance of environmental and social aspects: a) Strategic core elements leading directly to key earnings figures. b) Ecological or social leading indicators. c) Hygiene factors [22] are defining the relevant aspects. By using the top-down approach of the individual perspectives the causalities of the various aspects can be mapped to the sustainable success of the company. The influence of the identified leading indicators and lagging indicators on the higher-level perspective must be examined consistently. Thus, all environmental and social aspects can be aligned either directly or indirectly with the financial perspective and finally with the economic performance of the company.

Figure 4

Procedure for Formulation of a SBSC

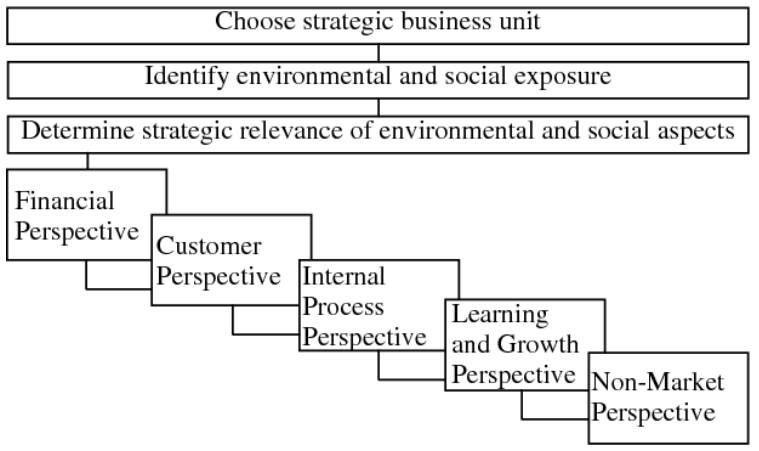




\section{Conclusion and recommendations}

The vision of sustainable development is not a mayfly and is a topical issue for more than $70 \%$ of large companies and more than $30 \%$ of all companies in Germany. The challenges facing our society and the companies operating in it can be identified ecologically in the reduction of raw material and energy consumption, socially in the demands for transparency and accountability to stakeholders and economically in the growing need for value orientation in environmental and social management.

Here the validity of an SBSC as an integrative concept comes to light which overcomes the previous deficits by identifying environmental and social aspects relevant to success and establishing causal links with the company's performance. Furthermore the management of the allocated aspects according to relevance is made possible and an integration of environmental and social management into general management is feasible. This can be manifested in improvements related to environmental- and social- effectiveness and enhancements in environmental- and social- efficiency. The openness of the SBSC also makes it possible that sustainability is not limited to a small number of companies that are primarily active in ecologically and socially oriented industries. The concept is therefore well suited for all companies that want to improve their performance in all three dimensions of sustainability regardless of size.

The following recommendations can be summarized from the findings in order to overcome the trade-off between profit orientation and sustainability alignment with the aim of generating an important contribution to the overall well-being of society:

- Formation of strategic alliances [23].

- Development of a systemic framework: The literature shows a lack of consensus on how to establish a clear link between SBSC architecture and environmental performance outcomes. As a result, a holistic conceptual framework in which SBSC knowledge acts as a mediator and the presence of experts as a facilitator could provide a more consistent relationship between SBSC architecture and environmental performance outcomes [24].

- Review and assurance of supply chain materiality through the SBSC. Explicit targets are to be formulated around the selected SDGs, including setting performance indicators and monitoring progress [25].

- Cooperation of technical disciplines with "Finance" and "Controlling" has to be intensified;

- Long-term risks and opportunities need to be taken into account;

- Be "1. Mover" and introduce CSR -with SBSC- into SME's. This can prevent future obligations that SME's will have to fulfil in the near term;

- Rewarding entrepreneurial (sustainability) activities through investment policy and public procurement and ratings as extrinsic incentives;

- Establishment of training measures, e.g. in mentoring programmes and founding circles of industry experts that communicate and cooperate transparently in order to exchange experiences;

- Introduction of longitudinal studies which, for example, are accompanied by universities and accumulate discovered improvement potential as "lessons learned" and transfer it into practice.

\section{References}

1. Figge, F., Hahn, T., Schaltegger, S. \& Wagner, M. Sustainability Balanced Score-card. Wertorientiertes Nachhaltigkeitsmanagement mit der Balanced Scorecard. Leuphana Universität Lüneburg, 6 (2001).

2. Lueg, K. Deconstructing corporate sustainability narratives: A taxonomy for critical assessment of integrated reporting types (2021).

3. BMU / BDI. Nachhaltigkeitsmanagement in Unternehmen; CSM; Universität Lüneburg, Schaltegger, Herzig, Kleiber, Müller (2002).

4. Hauff, Volker. Unsere gemeinsame Zukunft, Greven, 46 (1987).

5. Malay, OE; Aubinet, S. Improving government and business coordination through the use of consistent SDGs indicators. A comparative analysis of national and business sustainability indicators. Ecological Economics, 184, Art. No 106991 (2021).

6. Crossley, RM; Elmagrhi, MH, Ntim, C. G. Sustainability and legitimacy theory: The case of sustainable social and environmental practices of small and medium-sized enterprises. Business Strategy and the Environment, (2021).

7. Bieker, Thomas / Dyllik, Thomas/ Gminder, Carl-Ulrich / Hockerts, Kai. Management unternehmerischer Nachhaltigkeit mit einer Sustainability Balanced Scorecard. Forschungsmethodische Grundlagen und erste Konzepte, St. Gallen, 22, (2021). 
8. Pierobon, Marianna. Nachhaltigkeitsbewertung mit der Ökoeffizienz-Analyse, NTA4 - Vierte Konferenz des „Netzwerks TA“, Berlin, 22, (2010).

9. Gelbmann, U. \& Baumgartner, R. J. Strategische Implementierung von CSR in KMU. In A. Schneider \& R. Schmidpeter (Hrsg.), Corporate Social Responsibility: Verantwortungsvolle Unternehmensführung in Theorie und Praxis. Berlin, Heidelberg: Springer, (2012).

10. Europäische Kommission. Grünbuch. Europäische Rahmenbedingungen für die soziale Verantwortung der Unternehmen. Brüssel, 31, (2001).

11. Greiner, M., Sun, J. How corporate social responsibility can incentivize top managers: A commitment to sustainability as an agency intervention. Corporate Social Responsibility and Environmental Management, (2021).

12. Kober, R; Northcott, D. Testing cause-and-effect relationships within a balanced scorecard. Accounting and Finance, 61, 1815-1849 (2021)

13. Massingham, R. Improving integrated reporting; A new learning and growth perspective for the balanced scorecard, (2019).

14. Kaplan, R. und Norton, D. Using the Balanced Scorecard as a Strategic Management System. Harvard Business Manager, 75, (1996).

15. Dusch, Michael/Möller, M. Praktische Anwendung der Balanced Scorecard - Ein neuer Ansatz zur Fabriksteuerung in der Philips Bildröhrenfabrik Aachen. Controlling, 8, 119, (1997).

16. Horvath, Peter/Kaufmann, L. Balanced Scorecard - ein Werkzeug zur Umsetzung von Strategien. Harvard Business Manager, 20, (1998).

17. Ehrmann, H. Kompakt-Training Balanced Scorecard, 2. Aufl., Ludwigshafen, 50/186, (2002).

18. Kaufmann, L. ZP-Stichwort Balanced Scorecard. Zeitschrift für Planung, 8, 422 (1997).

19. Kaplan, R. und Norton, D. Balanced Scorecard. Strategien erfolgreich umsetzen, Stuttgart, 49, (1997).

20. Figge, F., Hahn, T., Schaltegger, S., Wagner, M. The Sustainability Balanced Scorecard Translating Strategy into Value - Based Sustainability Management. Conference Proceedings of the 2001 Business Strategy and the Environment in Leeds, UK. ERP Environment, Shipley, (2001)

21. Hansen, E. G., Schaltegger, S. The Sustainability Balanced Scorecard: A Systematic Review of Architectures, (2016).

22. Herzberg,F., Mausner. B., Snyderman, B. The motivation to work. 3 rd print., New Brunswick, NJ: Transaction Publishers, (1999).

23. Russo, A., Schena, R. Ambidexterity in the context of SME alliances: Does sustainability have a role? Corporate Social Responsibility and Environmental Management, 28, 606-615 (2021).

24. Jassem, S; Zakaria, Z; Azmi, A. C. Sustainability balanced scorecard architecture and environmental performance outcomes: a systematic review. International Journal of Productivity and Performance Management, (2021).

25. Claro, PBD, Esteves, N. R. Sustainability-oriented strategy and Sustainable Development Goals, Marketing Intelligence \& Planning, 39, 613-630 (2021). 